\title{
La responsabilidad civil de las clínicas y hospitales por infecciones nosocomiales
}

\section{The civil responsibility of clinics and hospitals for nosocomial infections}

\author{
Iván Darío Zuluaga Cardona
}

Artículo realizado como aporte académico del docente catedrático de derecho privado de la Facultad de derecho de la Universidad La Gran Colombia de Armenia.

Abogado especialista en derecho comercial y derecho constitucional. Estudiante de Maestría en derecho público. Docente catedrático de teoría de la obligación de la Universidad La Gran Colombia y Juez Civil del Circuito.

Fecha de recepción: 20 Septiembre de 2019

Fecha de aprobación: 11 de Dciciembre de 2019

Para citar este artículo / To reference this article Zuluaga, I.D. (2019) La responsabilidad civil de las clínicas y hospitales por infecciones nosocomiales. Inciso, 21, $257-272$.

\section{Resumen}

La responsabilidad civil por daños generados en el ejercicio de la medicina es un tema de amplia discusión y difusión en la actualidad, por la forma en cómo se ha concebido la prestación del derecho fundamental a la salud. El presente artículo tiene como propósito confrontar la tesis de responsabilidad subjetiva defendida por la Corte Suprema de Justicia, frente a la tesis de responsabilidad objetiva respaldada por el Consejo de Estado, en relación con la responsabilidad civil de las clínicas u hospitales por infecciones nosocomiales producidas por microorganismos multirresistentes a los antibióticos y con base en dicho paralelo, escoger aquella que se adecúa mejor al ordenamiento jurídico colombiano y a la realidad del sistema de salud. Para ello, se analizarán las complejas relaciones que se suscitan en la prestación de los servicios médicos cuando intervienen muchas personas y la imposibilidad de erradicar por completo este tipo de patógenos que dificultan la recuperación de pacientes, extienden la permanencia en centros hospitalarios y aumentan los costos y la mortalidad, para concluir que se debe acoger la tesis de responsabilidad subjetiva, porque se evidenció que sería imposible exonerarse de responsabilidad si se presume la culpa de los hospitales y clínicas. 
Palabras clave: Enfermedad, epidemiología, hospital, medicina clínica, responsabilidad civil.

Abstract

Civil liability for damages generated in the practice of medicine is a topic of wide discussion and dissemination today, due to the way in which the provision of the fundamental right to health has been conceived. The purpose of this article is to confront the thesis of subjective responsibility defended by the Supreme Court of Justice, against the thesis of objective responsibility supported by the State Council, in relation to the civil responsibility of the clinics or hospitals for nosocomial infections produced by Multi-resistant microorganisms to antibiotics and based on this parallel, choose one that best suits the Colombian legal system and the reality of the health system. For this, the complex relationships that arise in the provision of medical services when many people intervene and the inability to completely eradicate this type of pathogens that hinder the recovery of patients, extend the stay in hospital centers and increase costs will be analyzed. and mortality, to conclude that the subjective responsibility thesis must be accepted, because it was evidenced that it would be impossible to disclaim liability if the guilt of hospitals and clinics is presumed.

Keywords: Disease, epidemiology, hospital, clinical medicine, civil liability.

\section{Introducción}

Según datos de organismos internacionales (Organización Mundial de la Salud, 2010) las infecciones asociadas a la atención sanitaria (IAAS), también denominadas infecciones "nosocomiales" u "hospitalarias", son aquellas contraídas por un paciente durante su tratamiento en un hospital u otro centro sanitario y que este no tenía ni estaba incubando en el momento de su ingreso.

Por ello, para analizar el tema de la responsabilidad civil derivada de los daños que este tipo de infecciones puede generar en los prestadores del servicio, es importante hacer una sinopsis de cómo opera el sistema de salud en Colombia y los actores que intervienen en el mismo. La salud como derecho fundamental autónomo es en esencia un servicio público a cargo del Estado, por medio del cual se garantiza a todas las personas el acceso a los servicios de promoción, protección y recuperación, correspondiéndole, entre otros, establecer las políticas para la prestación de los servicios de salud por entidades privadas y ejercer su vigilancia y control.

Dentro de ese contexto que se deriva del artículo 49 de la norma constitucional, la relación médico-paciente que en otrora se concibió como privada, basada en la confianza ha caído en desuso para dar margen a convenios más complejos donde intervienen muchas personas en la prestación de los servicios de salud. Incluso, cada vez es más difícil ubicar la prestación del servicio en el campo contractual, puesto que la universalización del derecho a la salud y los deberes que para el cumplimiento del mismo se han impuesto a través de la Ley 1751 de 2015, no permiten analizar el tema 
desde la perspectiva del contrato de prestación de servicios médicos, que hace muchos años era intuito personae, cuando las personas acudían a su médico de confianza para atender sus dolencias físicas.

El nuevo enfoque normativo para la protección del derecho fundamental a la salud implica un deber de calidad e idoneidad profesional, según el cual los servicios deben estar centrados en el usuario, ser apropiados desde el punto de vista médico y técnico y responder a estándares de calidad aceptados por las comunidades científicas. Para cumplir esta misión se requiere personal de la salud adecuadamente competente, enriquecido con educación continua e investigación científica y una evaluación oportuna de la calidad de los servicios y tecnologías ofrecidos.

Ello genera como consecuencia que el derecho a la salud deba ser integral, es decir, incluyendo todos los servicios y tecnologías, suministrándolos de manera completa para prevenir, paliar o curar la enfermedad con independencia del origen de la enfermedad o condición de salud, del sistema de provisión, cubrimiento o financiación definido por el legislador, prohibiéndose la fragmentación de la responsabilidad de un servicio de salud específico en desmedro de la salud del usuario. Incluso se ha determinado una responsabilidad de tipo legal, al imponerse a todo prestador de servicios de salud, que cuando se trate de atención de urgencia, no se requerirá ningún tipo de autorización administrativa entre la IPS y la EPS para acceder a servicios y tecnologías de salud, lo que permite inferir que bajo esta óptica es posible una relación médico-paciente de tipo extracontractual.

Bajo ese complejo contexto, y atendiendo al objeto de este artículo, se analizará cómo la jurisprudencia colombiana ha atribuido responsabilidad civil de clínicas y hospitales por los daños generados a aquellos pacientes que han adquirido una infección nosocomial producida por un microorganismo multirresistente.

Lo contradictorio de esto es que la tesis de la Corte Suprema de Justicia es muy diferente a la esbozada por el Consejo de Estado, generando en la práctica que casos exactamente iguales se decidan en forma diferente, dependiendo de la naturaleza pública o privada del hospital o clínica generadora del daño. Para ello, este artículo pretende sin ser muy extenso sintetizar las tesis de ambas corporaciones, para que el lector asuma la que se considere más adecuada de acuerdo con lo que regula nuestro sistema normativo.

\section{¿Qué es un microorganismo multirresistente?}

Según la literatura médica (M.J. López-Pueyo, 2011), epidemiológicamente los microorganismos multirresistentes se definen como aquellos que son resistentes a una o más clases de antibióticos. Desde un punto de vista general la definición debe incluir al menos dos condiciones: que exista resistencia a más de una familia o grupo de antimicrobianos de uso habitual, que esa resistencia tenga relevancia clínica (es decir, que suponga o pueda suponer una dificultad para el tratamiento) y epidemiológica (posibilidad de brotes epidémicos, transmisión del mecanismo de resistencia, etc.). Aceptando estas condiciones, el término "microorganismo multirresistente" se ha 
utilizado sobre todo para bacterias clásicamente hospitalarias que han desarrollado resistencia a múltiples antimicrobianos, y que son capaces de ocasionar brotes. ${ }^{1}$

\section{¿Qué es una infección nosocomial?}

Cuando un paciente adquiere una bacteria multirresistente en su permanencia en una clínica u hospital, decimos jurídicamente hablando que ha contraído una infección nosocomial, lo cual ha conllevado en la práctica a un retraso en el inicio de la terapia adecuada, al aumento de los gastos y en muchos casos al fracaso terapéutico. La presencia de bacterias nosocomiales afecta gravemente la estabilidad económica del sistema de salud, pues atendiendo la forma en cómo está concebido el mismo, los hospitales de niveles bajos o con déficit de presupuesto no podrán adoptar todas las medidas necesarias para contrarrestar los nocivos efectos que produce la presencia de microorganismos multirresistentes.

La Organización Mundial de la Salud (OMS, 2010) en un informe publicado en su página web ha señalado que las infecciones nosocomiales pueden afectar a pacientes en cualquier tipo de entorno en el que reciban atención sanitaria, estas también permanecen hasta después de que el paciente reciba el alta. Asimismo, incluyen las infecciones ocupacionales contraídas por el personal sanitario, dichas infecciones son el evento adverso más frecuente durante la prestación de atención sanitaria, y ninguna institución ni país puede afirmar que ha resuelto el problema.

Según los datos de varios países, se calcula que cada año cientos de millones de pacientes de todo el mundo se ven afectados por infecciones nosocomiales. Cada día, este tipo de infecciones provocan la prolongación de las estancias hospitalarias, discapacidad a largo plazo, una mayor resistencia de los microorganismos a los antimicrobianos, enormes costos adicionales para los sistemas de salud, elevados costos para los pacientes y sus familias, así como muertes innecesarias.

Concluye su recomendación de página web (OMS, 2010) con las siguientes soluciones y medidas de mejora que se han identificado mediante el programa de la OMS "Una atención limpia es una atención más segura»:

- Identificar los determinantes locales de la carga de IAAS.

- Mejorar los sistemas de notificación y vigilancia a nivel nacional.

- Garantizar unos requisitos mínimos en lo que respecta a los establecimientos y los recursos disponibles destinados a la vigilancia de las IAAS a nivel institucional, incluida la capacidad de los laboratorios de microbiología.

- Garantizar el funcionamiento efectivo de los componentes fundamentales del control de las infecciones a nivel nacional y en los establecimientos de atención sanitaria.

\footnotetext{
1. Se consideran como tales: Staphylococcus aureus resistente a meticilina (SARM), Enterococcus spp. resistente a vancomicina (ERV), enterobacterias productoras de betalactamasas de espectro extendido (BLEE) y bacilos gramnegativos (BGN) no fermentadores como Acinetobacter baumannii o Pseudomonas aeruginosa resistentes a distintos grupos de antimicrobianos. Además, se suele calificar como multirresistentes a bacterias intrínseca o naturalmente resistentes a múltiples antimicrobianos, como Stenotrophomonas maltophilia o Clostridium difficile.
} 
- Aplicar las medidas generales de prevención, en particular las prácticas óptimas de higiene de las manos a la cabecera del paciente.

- Mejorar la educación y la responsabilización del personal.

- Realizar investigaciones para adaptar y validar los protocolos de vigilancia en función de las circunstancias de los países en desarrollo.

- Realizar investigaciones sobre la posible participación de los pacientes y sus familias en la notificación y el control de las IAAS. (OMS, 2010)

En el mismo artículo de la ciencia médica antes referido (López-Pueyo, 2011), se establecen otras estrategias más específicas para disminuir la incidencia de infección o colonización por microorganismo multirresistente así:

1. Desarrollar programas educacionales dirigidos a optimizar la utilización de los antibióticos.

2. Disminuir el tiempo de exposición a los principales factores de riesgo (ventilación mecánica, cateterización endovenosa y urinaria).

3. Mejorar los programas de vigilancia epidemiológica y microbiológica. Esta mejora incluye la introducción de sistemas de vigilancia activos que detecten precozmente los pacientes colonizados o infectados por gérmenes de especial relevancia. La vigilancia activa se basa en una valoración microbiológica sistemática en el momento del ingreso y posteriormente de forma periódica. La periodicidad dependerá del problema real que exista en cada unidad y de la capacidad de los servicios de Microbiología. Quizá la forma más extendida es la realización de muestras de rastreo al ingreso y con una periodicidad semanal.

4. Implementar las medidas de control que disminuyan la transmisión cruzada dentro de la unidad. Estas medidas incluyen tanto la optimización de la higiene de manos como el aislamiento, en general de contacto, cuando aparecen estos microorganismos. (M.J. López-Pueyo, 2011, pág. 45)

El cumplimiento de este protocolo genera costos económicos y administrativos que las clínicas y hospitales colombianos no pueden cumplir eficazmente, pues los ingresos del sistema de salud y la universalidad en la prestación de los servicios no permiten cubrir contingencias de este tipo, en donde prácticamente se obliga a que cada persona que ingresa a una unidad hospitalaria deba ser analizada por bacteriólogo, para determinar si tiene o no bacterias antes del ingreso a su hospitalización, premisa que aunque muy importante es de difícil cumplimiento por las deficiencias del sistema.

\section{El régimen de responsabilidad aplicable en los asuntos de naturaleza médica}

El Código de Ética Médica, contenido en la Ley 23 de 1981, determina que la relación médico-paciente es el elemento primordial en la práctica médica. Para que esta tenga pleno éxito debe fundarse en un compromiso responsable, leal y auténtico, el cual impone la más estricta reserva profesional. 
Sobre la responsabilidad en el ejercicio de su profesión, el citado estatuto precisa que el médico no expondrá a su paciente a riesgos injustificados, por lo tanto, debe pedir su consentimiento para aplicar los tratamientos médicos y quirúrgicos que considere indispensables y que puedan afectarlo física o síquicamente, salvo en los casos en que ello no fuere posible, y le explicará al paciente o a sus responsables de tales consecuencias anticipadamente.

Según las normas del derecho positivo, la responsabilidad del médico por reacciones adversas, inmediatas o tardías, producidas por efecto del tratamiento no irá más allá del riesgo previsto, dejando por fuera entonces aquellos casos donde los riesgos son previstos, pero de rara ocurrencia, los que recaen sobre instituciones o personas jurídicas que cumplen funciones administrativas en conexión con el derecho a la salud o frente a clínicas u hospitales por el deber de custodia que tienen con sus pacientes internados.

La responsabilidad médica ha sido definida por Fonseca ( 2014), como el compromiso del profesional de la medicina con el fin de atribuir la obligación de resarcir los perjuicios causados al paciente que sufrió un daño en su vida o integridad física producto de la conducta culposa del galeno, ya sea por negligencia, imprudencia, impericia o desconociendo reglamentos sobre la prestación del servicio a la salud o cuando se aparte de la lex artis.

El exmagistrado Carlos Ignacio Jaramillo (2011) ha precisado que la curación o el restablecimiento de la salud, desborda el débito galénico, puesto que ello no depende de la conducta desplegada por el médico, ni menos del grado de diligencia por él empleado, en la medida que para dicho logro se requiere la concurrencia armónica y eficiente de factores como la edad del paciente, el medio o entorno en que vive, la genética y el álea de su capacidad de asimilación farmacéutica.

Sobre la responsabilidad de los hospitales, que es el tema de análisis en este artículo, el exmagistrado Javier Tamayo Jaramillo (2007) indicó que el hospital tiene la obligación de resultado que al paciente nada le ocurra dentro de sus instalaciones, a no ser que el daño se produzca por un comportamiento activo de aquel, en cuyo caso la obligación sería de medio.

La jurisprudencia nacional (Sentencia, SN, 2010) ha resaltado que si bien el pacto de prestación del servicio médico puede generar diversas obligaciones a cargo del profesional que lo asume, y que atendiendo a la naturaleza de estas dependerá, igualmente, su responsabilidad, no es menos cierto que tratándose de la ejecución del acto médico propiamente dicho, deberá indemnizar en línea de principio y dejando a salvo algunas excepciones los perjuicios que ocasione mediando culpa, en particular la llamada culpa profesional, o dolo, cuya carga probatoria asume el demandante, sin que sea admisible un principio general encaminado a establecer de manera absoluta una presunción de culpa de los facultativos.

En una jurisprudencia más reciente, el precedente de la Corte Suprema de Justicia (Sentencia SC003, 2018) resaltó que causada una lesión o menoscabo en la salud, con 
ese propósito, el afectado debe demostrar como elementos axiológicos integradores de la responsabilidad médica la conducta antijurídica, el daño y la relación de causalidad entre este y aquélla, así como la culpabilidad, según la naturaleza de la responsabilidad (subjetiva u objetiva) o de la modalidad de las obligaciones de que se trata (de medio o de resultado). En el campo dicho, porque el artículo 26 de la Ley 1164 de 2007, alusiva al talento humano en salud, con la modificación introducida por el canon 104 de la Ley 1438 de 2011, establece que la relación médico-paciente "genera una obligación de medio" sobre la base de una competencia profesional, en clara distinción con las de resultado, estas últimas, en virtud de "estipulaciones especiales de las partes" (Inciso último artículo 1604 del Código Civil).

La diferencia entre obligaciones de medio y de resultado, por lo tanto, sirve para facilitar y solucionar problemas relacionados con la culpa galénica y su prueba, sin perjuicio, claro está, de otras reglas de morigeración, cual ocurre en los casos de una evidente dificultad probatoria para el paciente o sus familiares, todo según las circunstancias en causa, introducidas ahora por el artículo 167 del Código General del Proceso.

\section{La imputación del daño a las empresas promotoras de salud y a las instituciones prestadoras del servicio}

Quedando establecido entonces que la responsabilidad médica requiere una prueba de la culpa del médico tratante, el tema se hace más confuso cuando la prestación del servicio se hace dentro de entramado del sistema general de seguridad social en salud, en donde interviene una empresa promotora de salud que autoriza los medicamentos, procedimientos o servicios, una institución prestadora de servicio que tiene contrato con la EPS y el médico adscrito a la IPS que tiene relación directa con el paciente.

La culpa médica generadora de responsabilidad civil puede provenir de cualquiera de los agentes que intervienen en el proceso, ya sea por dilación injustificada en las autorizaciones o negación de servicios, demoras en la asignación de citas, imposición de barreras u obstáculos administrativos que dilatan los servicios de urgencia o suspenden la continuidad de los tratamientos, por último, por mala praxis del equipo de profesionales adscritos a las instituciones prestadoras de salud.

Como puede observarse, existen relaciones laborales complejas que podrían generar confusión a la hora de establecer el causante directo del daño. Previendo esta dificultad la jurisprudencia de la Corte Suprema de Justicia (Sentencia SC8219, 2016), a manera de precedente, estableció el principio de solidaridad entre todos los agentes que hacen parte del sistema de salud en Colombia, dando a entender con esto que cualquiera que genere un daño y se le logre demostrar la culpa hace responsables civilmente a todos los demás, con excepción de los agentes individuales o médicos, a quienes se les deberá probar su culpa exclusivamente.

Como ratio decidendi, el citado precedente señaló que a pesar de los avances en medicina, la complejidad del cuerpo humano impide que hoy en día esta ciencia pueda brindar resultados absolutos o asegurar resultados satisfactorios en todos los casos, de 
ahí que se estime que su práctica, en términos generales, corresponde a una obligación de medio. Es por eso que solo si se verifica una mala praxis surge la obligación de reparar, entre otros eventos, cuando se deja de actuar injustificadamente conforme a los parámetros preestablecidos, eso sí, siempre y cuando se estructuren los diferentes elementos de daño, culpa y nexo causal que contempla la ley.

Los artículos 177 al 179 y 185 de la Ley 100 de 1993 que se refieren en su orden a la definición de las entidades promotoras de salud, sus funciones, campo de acción y los límites de acción de las instituciones prestadoras de servicios de salud, de ninguna manera restringen la correlación que existe entre ambas clases de entidades para los efectos de la responsabilidad civil derivada de la atención médica.

Por el contrario, el primero es específico en que la función básica de las E.P.S. será organizar y garantizar, directa o indirectamente, la prestación del Plan de Salud Obligatorio a los afiliados, lo que conlleva una carga de velar porque aquella sea óptima, con las consecuencias que se derivan de su desatención, ya sea que el afiliado o sus beneficiarios acudan a los centros asistenciales propios o aquellos contratados con ese fin.

Incluso el artículo 227 de la Ley 100 de 1993 fijó como una obligación de las E.P.S. desarrollar sistemas de: garantía de calidad de la atención de salud, incluyendo la auditoría médica, de acuerdo con la normatividad expedida por el Gobierno, reforzando más su poder de vigilancia y control.

En posterior pronunciamiento la misma corporación $(S C 13925,2016)$ reiteró el tema de la solidaridad entre los agentes, precisando que la atención médica de hoy en día requiere habitualmente que los pacientes sean atendidos por varios médicos y especialistas en distintas áreas, incluyendo atención primaria, ambulatoria especializada, urgencias, quirúrgica, cuidados intensivos y rehabilitación. Los usuarios de la salud se mueven regularmente entre áreas de diagnóstico y tratamiento que pueden incluir varios turnos de personas por día, por lo que el número de agentes que están a cargo de su atención puede ser sorprendentemente alto.

Todas esas personas podrían tener un influjo decisivo en el desenvolvimiento causal del resultado lesivo; sin embargo, para el derecho civil no es necesario, ni posible, ni útil realizar un cálculo matemático del porcentaje de intervención de cada elemento de la organización en la producción física del evento adverso. Para atribuir la autoría a los miembros particulares, basta con seleccionar las operaciones que el juez considera significativas o relevantes para endilgar el resultado a uno o varios miembros de la organización.

De manera que para imputar responsabilidad a los agentes singulares de la organización, eljuez habrá de tomar en cuenta solo aquellas acciones, omisiones o procesos individuales que según su marco valorativo incidieron de manera preponderante en el daño sufrido por el usuario y cargarlos a la cuenta de aquellos sujetos que tuvieron control o dominio en la producción del mismo. De este modo, se atribuye el hecho dañoso a un agente 
determinado, quien responderá en forma solidaria con la EPS y la IPS, siempre que confluyan en ellos todos los elementos de la responsabilidad civil.

El agente médico singular se exonerará del juicio de imputación del hecho como suyo siempre que se demuestre en el proceso que no tenía un deber de cuidado en la atención que brindó al paciente, lo que ocurre, por ejemplo, cuando su intervención no fue jurídicamente relevante o estuvo amparada en una causal de justificación de su conducta; cuando el daño se debió al quebrantamiento de una obligación de acción de la EPS o de la IPS y no a la desatención del deber personal de actuar; o cuando no intervino de ninguna manera ni tenía el deber jurídico de hacerlo.

Así, por ejemplo, si se demuestra en el proceso que el evento adverso se produjo por falencias organizacionales; errores de coordinación administrativa; políticas empresariales que limitan al médico en la utilización del tiempo que requiere para brindar una atención de calidad al usuario; o restringen su autonomía para prescribir los procedimientos, medicamentos o tratamientos que se requieren para la recuperación de la salud del usuario, tales como exámenes de laboratorio, imágenes diagnósticas o ecografías, tomografías axiales computarizadas, etc., o cualquier otra razón atribuible a las empresas promotoras o a las instituciones prestadoras del servicio de salud, entonces los agentes médicos quedarán exonerados de responsabilidad porque el daño ocasionado al cliente del sistema de salud no podrá considerarse como obra suya sino de la estructura organizacional.

\section{Precedentes sobre la responsabilidad de clínicas y hospitales por daños generados por infecciones nosocomiales. Confrontación de la tesis de responsabilidad subjetiva la Corte Suprema de Justicia con la tesis de responsabilidad objetiva del Consejo de Estado}

La Corte Suprema de Justicia ha sentado doctrina probable sobre este tema en reciente sentencia (SC2202, 2019) donde la alta Corporación estableció algunas sub reglas que constituyen un precedente jurisprudencial de obligatorio cumplimiento en relación con la responsabilidad de los hospitales y clínicas por los daños generados a los pacientes por la presencia de bacterias nosocomiales, bajo el título de imputación de la responsabilidad por incumplimiento de las obligaciones de seguridad del deudor en relación con la integridad física y los bienes del acreedor que está bajo su custodia.

Como sustento de este débito de seguridad, se indicó que supone para clínicas y hospitales la implementación y mantenimiento de medidas dirigidas a prevenir accidentes e infecciones, sobre la base de un control estricto acorde con protocolos contentivos de normas técnicas adoptados por el propio centro de salud o exigidos por las autoridades que tienen a su cargo su inspección, vigilancia y control, y que se extienden pero no se limitan a la señalización, transporte adecuado de enfermos, dotación infraestructural apropiada, métodos de limpieza y esterilización, procedimientos de seguridad, desinfección, control de visitas, identificación, idoneidad e inspección en materia de salud del personal, coordinación de tareas con el fin de aminorar errores en procesos, disposición de residuos orgánicos, recintos especializados, entre muchas otras variables. 
Precisa que esta obligación de seguridad no puede catalogarse como de resultado en tratándose de agentes patógenos cuyo control eficaz ha fracasado hasta la fecha a nivel mundial, de donde resulta evidente que la aleatoriedad del resultado indeseado de que el paciente adquiera una enfermedad intrahospitalaria constituye un evento que puede escapar al control de la entidad nosocomial.

La doctrina probable se puede sintetizar, a la luz del derecho privado, en entender que la obligación de seguridad a cargo de centros de salud y hospitales, es dable subclasificarla en atención a la aleatoriedad e imposibilidad de controlar factores y riesgos que inciden en los resultados. Por ello, es de medio la obligación de seguridad a cargo de estos establecimientos de hacer lo que esté a su alcance con miras a que su paciente no adquiera en su recinto enfermedades diferentes de las que lo llevaron a hospitalizarse.

La carga de la prueba entonces, en ese contexto, recae en el hospital o clínica, puesto que al tratarse de una obligación de prudencia y diligencia, deberá acreditar el cumplimiento de los protocolos y normas técnicas tendientes a evitar las infecciones nosocomiales de pacientes internados.

Contrario a lo hasta aquí expuesto, el Consejo de Estado, ha creado la tesis de una responsabilidad objetiva (presunción de culpa de los hospitales) fundada en que la obligación de seguridad es siempre de resultado.

La jurisprudencia de la jurisdicción contencioso administrativa (Sentencia 30283, 2013), al defender la tesis expuesta, sentó las siguientes reglas:

Tratándose específicamente de la responsabilidad por infecciones nosocomiales, existe en el derecho comparado una clara tendencia orientada hacia la objetivización de la responsabilidad de los establecimientos de salud, en virtud de la cual al paciente le basta con demostrar que el daño que padece es consecuencia de una enfermedad adquirida durante su permanencia en el centro hospitalario.

En nuestro país, el marco teórico de la responsabilidad aplicable a los casos de infecciones nosocomiales o intrahospitalarias, ha sido poco desarrollado por la jurisprudencia. No obstante, existen algunos escasos pronunciamientos de esta Corporación en los que el tema ha sido mencionado para efectos de señalar que los daños derivados de este tipo de infecciones no pueden ser considerados como "eventos adversos", asociados al incumplimiento de la obligación de seguridad y vigilancia jurídicamente exigible a las instituciones prestadoras de servicios de salud, sino que deben ser analizados desde un régimen objetivo de responsabilidad. Se tiene así que el Consejo de Estado, si bien no se ha ocupado de desarrollar una dogmática específica aplicable a los casos de daños derivados de infecciones nosocomiales en los que no existe falla probada del servicio, sí ha trazado unas primeras pautas para afirmar, en consonancia con la tendencia que impera en el derecho comparado, que estos deben ser analizados desde un régimen objetivo de responsabilidad, que sería el de riesgo excepcional. 
De las cuatro modalidades de riesgo aceptadas por la jurisprudencia de esta Corporación (riesgo-peligro, riesgo-beneficio, riesgo-conflicto y riesgo-álea) la Sala considera que ésta última es la más apropiada para imputar jurídicamente responsabilidada la administración por los daños derivados de infecciones intrahospitalarias, teniendo en cuenta que esta categoría de riesgo toma en consideración la probabilidad de que "cierto tipo de actividades o procedimientos, pueden dar lugar, quizás con la ineludible mediación del azar o de otro tipo de factores imprevisibles, a la producción de daños sin que medie asomo alguno de culpa". Hasta el momento, la aplicación de la categoría de riesgo-álea, que encuentra su origen en la jurisprudencia francesa, se ha reservado hasta en nuestro medio a aquellos supuestos en los que el daño se produce por la utilización de un aparato o instrumento empleado por la ciencia médica para el diagnóstico o tratamiento de ciertas enfermedades o patologías o por la ejecución de ciertos procedimientos para el mismo fin (...) la Sala considera que nada obsta para hacer extensiva la categoría de riesgo-álea a los casos en los cuales el daño es consecuencia de una infección contraída en un centro asistencial como quiera que en todas estas situaciones el daño surge por la concreción de un riesgo que es conocido por la ciencia médica, pero que se torna irresistible en tanto su concreción depende, muchas veces, de la "ineludible mediación del azar".

Los hechos irresistibles, por regla general, no comprometen la responsabilidad patrimonial de la administración en razón a que pueden ser calificados como "casos fortuitos". No obstante, tratándose de las infecciones nosocomiales, la Sala considera, junto con un sector de la doctrina, que no pueden ser calificadas como casos fortuitos porque no son ajenas a la prestación del servicio público de salud. Tampoco puede considerarse, para efectos de exonerar de responsabilidad a la administración por los daños derivados de infecciones nosocomiales, que estas encajan dentro de lo que la doctrina denomina como "riesgos del desarrollo", pues este concepto se refiere específicamente a aquellos eventos, que no solo son irresistibles, sino también imprevisibles. Las infecciones intrahospitalarias, según ya se señaló, si bien pueden llegar a ser irresistibles, no son imprevisibles pues constituyen un riesgo conocido por la ciencia médica, además, son prevenibles y controlables, al punto de que la tasa de incidencia de infecciones nosocomiales en los pacientes de un establecimiento determinado es un indicador de la calidad y seguridad de la atención.

En criterio del Consejo de Estado, el riesgo puede servir como factor para atribuir jurídicamente responsabilidad a la administración por los daños causados como consecuencia de una infección de carácter intrahospitalario, entendida como aquella que se contrae por el paciente en el hospital o centro asistencial. En estos eventos la responsabilidad es de carácter objetivo, por lo que la parte demandada para liberarse de la obligación de indemnizar los perjuicios, tendrá que demostrar que el paciente ya portaba el cuadro infeccioso antes de ingresar al nosocomio.

Aunque las infecciones nosocomiales pueden llegar a ser irresistibles, son prevenibles y controlables, por lo que está en manos de las entidades hospitalarias adoptar todas las medidas establecidas en los protocolos diseñados por las autoridades competentes 
a efectos de reducir los riesgos que comporta para los pacientes, en especial para aquellos que resultan más vulnerables como los niños, las personas de la tercera edad y quienes padecen de enfermedades crónicas, el uso de cierto instrumental médico, la permanencia prolongada en los establecimientos hospitalarios y el contacto directo o indirecto con otros pacientes infectados. Así mismo, es tarea de las autoridades encargadas del control y vigilancia de la prestación de los servicios de salud, velar porque estas medidas se cumplan, así como monitorear la incidencia de las infecciones nosocomiales en los centros hospitalarios tanto de carácter público como privado con fin de promover la implementación de estrategias para identificar las prácticas en la atención clínica que favorecen la aparición del riesgo de este tipo de infecciones y que repercuten negativamente en los indicadores de calidad de la atención en salud.

Esta tesis es reiterada posteriormente (Sentencia 28214, 2014, págs. 20, 21) y adicionada en la prueba de los orígenes de la infección, con base en la diferenciación entre dos supuestos de hecho:

(i) El caso en el que el paciente adquiere la bacteria causante de la infección en el hospital o clínica en donde está siendo atendido por otro asunto de salud, lo que se conoce como origen exógeno de la infección, y

(ii) El caso en el que el paciente traía consigo la bacteria que generó la afectación, pero como consecuencia de la intervención quirúrgica o procedimiento invasivo circunstancia que puede romper las barreras naturales de defensa de los organismos vivos-, se desató la infección causante del daño (translocación bacteriana), lo que se conoce como infección de origen endógeno.

Concluye la tesis del Consejo de Estado que para dar aplicación al régimen objetivo de responsabilidad por daños derivados de la adquisición de una bacteria nosocomial, deberán probarse los siguientes elementos:

a) Que el daño tuvo su origen en una infección de origen exógeno al paciente,

b) Que el daño fue ocasionado por una bacteria multirresistente y

c) Que resultó inevitable para la institución la producción del mismo - porque de haber sido evitable se trataría eventualmente de una falla el servicio-, esto es, la constatación de que se ha concretado el riesgo aleatorio al que están sometidos los usuarios del sistema de salud y que en términos de distribución de cargas resultaría excesivo imponerla al paciente. (Sentencia 28214, 2014, pág. 35)

Por último, respecto de los eximentes de responsabilidad es importante la diferenciación del origen exógeno/endógeno, toda vez que la parte demandada puede exonerarse de responsabilidad cuando el origen del daño le fue ajeno, es decir, cuando la infección adquirida fue de origen endógeno del organismo del paciente. Sin embargo, esta situación no puede confundirse con aquella en la que el paciente no traía en su cuerpo el agente patógeno, sino que lo adquirió en el nosocomio, pero se aducen sus condiciones 
de particular vulnerabilidad para sustraer la responsabilidad de la institución de salud, pues en estos casos sí es aplicable el régimen de responsabilidad objetiva del que se ha hablado. Lo anterior, por cuanto las personas que acuden a los centros de salud son en su mayoría niños, ancianos, o jóvenes, pero que se encuentran en situación de enfermedad o anomalía en su salud, lo que per se les hace vulnerables a la adquisición de infecciones ocasionadas por aquellas bacterias que habitan en los hospitales, y que precisamente por habitar allí se han adaptado, convirtiéndose en multirresistentes.

Es por eso que en las unidades de cuidados intensivos y en general en las instalaciones de clínicas y hospitales deben extremarse las medidas de prevención de adquisición de infecciones de carácter nosocomial.

\section{Conclusiones}

La tesis que podemos denominar de responsabilidad subjetiva sustentada por la Corte Suprema de Justicia se puede sintetizar así:

\begin{tabular}{|l|l|}
\hline Tipo de responsabilidad & $\begin{array}{l}\text { Subjetiva: Se debe probar la culpa del hospital o clínica, por } \\
\text { negligencia en el cumplimiento de los protocolos. }\end{array}$ \\
\hline ¿Qué debe probar el paciente que demanda? & $\begin{array}{l}\text { Que el daño que padece es consecuencia de una enfermedad } \\
\text { adquirida durante su permanencia en el centro hospitalario. }\end{array}$ \\
\hline ¿Bajo qué título de imputación se debe analizar el tema? & $\begin{array}{l}\text { Incumplimiento de la obligación de medio de seguridad, } \\
\text { consistente en evitar que el paciente contraiga infecciones } \\
\text { intrahospitalarias. }\end{array}$ \\
\hline Elementos para la prosperidad de la acción & $\begin{array}{l}\text { Probar que el daño tuvo su origen en una infección de origen } \\
\text { exógeno al paciente, es decir, que la adquirió dentro del } \\
\text { hospital. } \\
\text { Que el daño fue ocasionado por una bacteria multirresistente. } \\
\text { Que el hospital o clínica no logre demostrar debida diligencia } \\
\text { y cuidado para evitar el contagio del paciente }\end{array}$ \\
\hline$¿$ Cómo se puede exonerar de responsabilidad el \\
hospital? \\
$\begin{array}{l}\text { Además de la causa extraña, demostrando que empleó } \\
\text { medios idóneos de acuerdo con las normas técnicas y } \\
\text { protocolos para tratar de evitar el contagio, es decir, } \\
\text { demostrando debida diligencia y cuidado. Para ello, puede } \\
\text { probar el cumplimiento de las recomendaciones de la OMS } \\
\text { yde la literatura médica. }\end{array}$ \\
\hline
\end{tabular}

Por su parte, la tesis de responsabilidad objetiva sustentada por el Consejo de Estado se sintetiza así: 


\begin{tabular}{|l|l|}
\hline Tipo de responsabilidad & Objetiva: presunción de culpa del hospital o clínica \\
\hline ¿Qué debe probar el paciente que demanda? & $\begin{array}{l}\text { Que el daño que padece es consecuencia de una enfermedad } \\
\text { adquirida durante su permanencia en el centro hospitalario. }\end{array}$ \\
\hline ¿Bajo qué título de imputación se debe analizar el tema? & $\begin{array}{l}\text { Riesgo excepcional en la modalidad riesgo-álea, consistente } \\
\text { en que el daño surge por la concreción de un riesgo que es } \\
\text { conocido por la ciencia médica, pero que se torna irresistible } \\
\text { en tanto su concreción depende muchas veces de la } \\
\text { ineludible mediación del azar. }\end{array}$ \\
\hline Elementos para la prosperidad de la acción & $\begin{array}{l}\text { Probar que el daño tuvo su origen en una infección de origen } \\
\text { exógeno al paciente, es decir, que la adquirió dentro del } \\
\text { hospital. } \\
\text { Que el daño fue ocasionado por una bacteria multirresistente } \\
\text { Que la producción del daño resultó inevitable para la } \\
\text { institución }\end{array}$ \\
\hline ¿Cómo se puede exonerar de responsabilidad el hospital \\
$\begin{array}{l}\text { Demostrando el origen endógeno de la bacteria, es decir, que } \\
\text { el paciente ya portaba el cuadro infeccioso antes de ingresar } \\
\text { al nosocomio. }\end{array}$ \\
\hline
\end{tabular}

De la simple confrontación de ambas posiciones se considera más ajustada al ordenamiento jurídico colombiano, la tesis de responsabilidad subjetiva defendida por la Corte Suprema de Justicia por los siguientes argumentos:

Porque el Consejo de Estado, acudiendo al derecho comparado permite que hechos irresistibles comprometan la responsabilidad bajo un título de imputación de presunción de culpa, sin fundarse en una norma de derecho interno o del bloque de constitucionalidad que sea la fuente formal de imputación jurídica.

La tesis de la responsabilidad objetiva se contradice al decir que las bacterias nosocomiales son previsibles, pero a renglón seguido precisan que resulta imposible erradicarlas totalmente de los hospitales, añadiendo que la ciencia médica informa que aún en las condiciones más óptimas de higiene es posible hallarlas.

¿Cómo es posible entonces prever una infección nosocomial si no hay forma de erradicarlas totalmente? Es una contradicción fáctica que tiene serias consecuencias jurídicas, pues la previsibilidad advertida por el Consejo de Estado, fue la que le quita el carácter de caso fortuito a la infección por bacteria multirresistente.

Se recuerda que el caso fortuito en todo tipo de responsabilidad, constituye un rompimiento del nexo causal, salvo las excepciones previstas en la ley.

Por tal virtud, los argumentos de responsabilidad objetiva no pueden ser aplicados a asuntos contractuales de naturaleza civil, porque riñen con lo estipulado por el artículo 1604 inciso 2 del Código Civil, según el cual el deudor no es responsable del caso fortuito, a menos que se haya constituido en mora o que el caso fortuito haya sobrevenido por su culpa.

Significa lo anterior que el daño ocasionado por un caso fortuito (bacteria nosocomial) debe llevar implícito un tema de responsabilidad subjetiva, pues la norma civil condiciona 
el no rompimiento del nexo causal a que el deudor de la prestación haya causado el caso fortuito por su culpa.

Incluso, es aplicable en este asunto el inciso 2 del artículo 1616 del Código Civil al precisar que la mora producida por caso fortuito no da lugar a indemnización de perjuicios.

Por último, la tesis del Consejo de Estado no ofrece una solución pacífica a la enorme dificultad probatoria que reviste para los hospitales y clínicas de probar el origen endógeno o exógeno de la infección, permitiendo que se condene al demandado por daños de los cuales hay dudas del nexo causal.

El caso fortuito en materia civil corresponde probarlo a quien lo alega (artículo 1604 inciso 3), entonces si la bacteria multirresistente es la causa del daño, ¿qué debe probar el hospital? Podría considerarse una especie de prueba diabólica.

En conclusión, no es posible aplicar las reglas trazadas por el Consejo de Estado para la responsabilidad por infecciones nosocomiales de hospitales y clínicas en asuntos de naturaleza civil, bajo el título de imputación de responsabilidad objetiva, puesto que se desconocen normas que rigen el derecho interno, se desnaturaliza el fenómeno del caso fortuito como eximente de responsabilidad y su forma de probarlo, generando un desequilibrio probatorio que no tiene una proporcionalidad justificada.

A nuestro juicio, la responsabilidad de hospitales y clínicas por bacterias multirresistentes debe resolverse siguiendo la tesis de la Corte Suprema de Justicia, bajo el régimen de responsabilidad subjetiva de culpa probada, caso en el cual el demandante deberá demostrar el origen de la infección y la parte demandada podrá exonerarse si logra probar debida diligencia y cuidado a la hora de adoptar los protocolos de asepsia de instrumentos y quirófanos.

Pueden servir de parámetro para los fines de este artículo que las clínicas y hospitales prueben como respaldo de su debida diligencia y cuidado el cumplimiento de las recomendaciones generales dadas por la OMS (Organización Mundial de la Salud, 2010) y por la literatura médica (M.J. López-Pueyo, 2011) para contrarrestar los efectos de las infecciones intrahospitalarias.

Esto, porque la bacteria nosocomial, por su naturaleza misma, es un caso fortuito y por ende solo genera responsabilidad contractual en caso de mora del deudor en el cumplimiento de la prestación o que el caso fortuito haya sobrevenido por su culpa.

\section{Referencias bibliográficas}

CorteSuprema de Justicia, Sala de Casación Civil.(22 dejulio de2010). Sentencia SN-2010. M. P. Pedro Octavio Munar Cadena. Recuperado de http://legal.legis.com.co/document/ Index?obra=jurcol\&document=jurcol_8c60891b6bb66096e0430a0101516096

Consejo de Estado, Sala de lo Contencioso Administrativo, Sección Tercera - Subsección B. (29 de agosto de 2013). Sentencia 30283. M. P. Danilo Rojas Betancourth. 
Recuperado de: http://legal.legis.com.co/document/Index?obra=jurcol\&document=jurcol_e82699e3b60d005ee0430a010151005e

Consejo de Estado, Sala de lo Contencioso Administrativo, Sección Tercera - Subsección B. (30 de abril de 2014). Sentencia 28214. M. P. Danilo Rojas Betancourth. Recuperado de: http://consejodeestado.gov.co/documentos/sentencias/2500023260002001019 6001.pdf

Corte Suprema de Justicia, Sala de Casación Civil. (20 de junio de 2016). Sentencia Sc8219-2016. M. P. Fernando Giraldo Gutiérrez. Recuperado de: http://www. cortesuprema.gov.co/corte/wp-content/uploads/relatorias/ci/doctri2016/ Sc8219-2016\%20(2003-00546-01).doc

Corte Suprema de Justicia, Sala de Casación Civil. (30 de septiembre de 2016). Sentencia Sc13925-2016. M. P. Ariel Salazar Ramírez. Recuperado de: http://www.cortesuprema. gov.co/corte/index.php/2016/11/01/sc13925-2016/

Corte Suprema de Justicia, Sala de Casación Civil. (12 de enero de 2018). Sentencia Sc003-2018. M. P. Luis Armando Tolosa VIllabona). Recuperado de: http:// www.cortesuprema.gov.co/corte/wp-content/uploads/relatorias/ci/gene2018/ Sc003-2018\%20(2012-00445-01).doc

Corte Suprema de Justicia, Sala de Casación Civil. (20 de junio de 2019). Sentencia SC2202-2019. M. P. Margarita Cabello Blanco). Recuperado de: http://www. cortesuprema.gov.co/corte/wp-content/uploads/2019/09/SC2202-2019-200600280-01_compressed.pdf

Fonseca, J. L. (Enero-Junio de 2014). Responsabilidad y culpa médica: antecedentes y conceptos. Revista Académica y Derecho 5, 173-192. Recuperado de: file:///C:/Users/ Izuluagac/Downloads/Dialnet-ResponsabilidadYCulpaMedica-6713667.pdf

Jaramillo, C. I. (2011). Responsabilidad Civil Médica. La relación médico-paciente. Bogotá D.C.: Ibañez.

M.J. López-Pueyo, F. B.-G.-V.-M. (2011). Multirresistencia antibiótica en unidades de críticos. Medicina intensiva, 41-53. Recuperado de: http://scielo.isciii.es/pdf/medinte/ v35n1/puesta.pdf

Organización Mundial de la Salud. (10 de Diciembre de 2010). Carga Mundial de infecciones asociadas a la atención sanitaria. The Lancet. Recuperado de: https://www. who.int/gpsc/country_work/burden_hcai/es/

Tamayo, J. (2007). Tratado de Responsabilidad Civil. Bogotá D.C.: Legis. 